\title{
THE WEIRD AND THE WONDERFUL - THE SCIENTIFIC STUDY OF A MINIATURE MUMMY
}

\author{
Lidija M. McKnight ${ }^{1}$, Natalie C. McCreesh ${ }^{1}$, Andrew Gize ${ }^{2}$ \\ ${ }^{1}$ KNH Centre for Biomedical Egyptology, \\ University of Manchester, Manchester, UK \\ ${ }^{2}$ School of Earth, Atmospheric and Environmental Sciences, \\ University of Manchester, Manchester, UK
}

\begin{abstract}
A human-faced oddity purported to be a 'human baby, animal mummy or fake' constructed in an ancient Egyptian style, was analysed at the $\mathrm{KNH}$ Centre for Biomedical Egyptology, University of Manchester, UK. Radiographic analysis using conventional radiography (X-ray) and computed tomography (CT) highlighted the nature of the bundle contents and identified marked similarities to mummified animal remains from ancient Egypt. Small samples were analysed using microscopy, environmental scanning electron microscopy (ESEM) and energy dispersive spectroscopy (EDS). ESEM was used to assess the homogeneity of the sample and the materials used in its construction. EDS was conducted for analysis of the elemental composition.

Comparatively few miniature mummies of this type are known and they represent an intriguing area of mummy studies. The results of this research have allowed comparisons with contemporary human and animal mummies to be made.

Based on residues of tin plating found on the underside of the mask, it is possible that this feature is a recent addition. Further analysis of the materials used in the construction of the artefact is required to ascertain if the mask is a contemporary feature.
\end{abstract}

Keywords: mummy, pseudo, radiography, ESEM, EDS 


\section{INTRODUCTION}

Ha6370, a small, mummified object presented in a wooden, glass-topped coffin, was donated to the Bristol Museum and Art Gallery in 1857 by Robert Walker with a label stating it to be the 'mummy of a cat'. The original acquisition records describe the specimen as a 'human baby, animal mummy or fake' presumably because of its small dimensions $(360 \mathrm{~mm} \times 120 \mathrm{~mm})$ and its eerie human features. No further details relating to conservation history, geographic or chronological provenance are known.

\section{MATERIALS AND METHODS}

Visual examination of the miniature mummy reveals a solid, dark brown bundle, cylindrical in shape with a textured outer surface. The head depicts human features. The wooden, glass-lidded anthropoid coffin in which the specimen is presented is modern and closes to one side with a small brass clasp (Fig. 1). The interior of the coffin has been lined with a layer of paper decorated with Egyptian motifs.
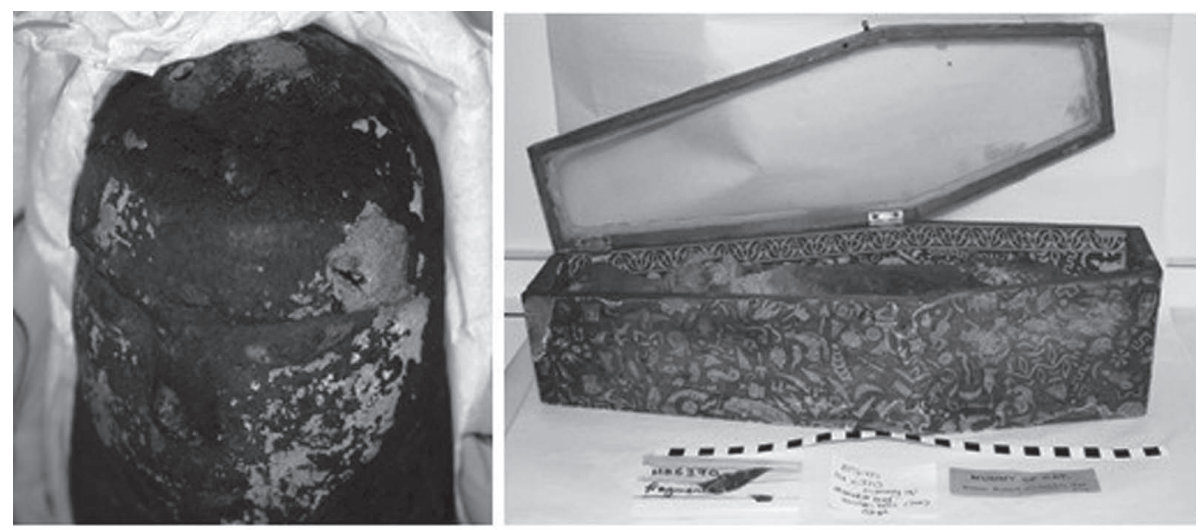

Figure 1. Photographs of Ha6370 showing the modelled mask with painted features and the presentation of the specimen in the modern anthropoid coffin (courtesy Bristol City Council. Image by Lidija McKnight).

Assessment of the wrappings and contents was possible macroscopically due to an area of damage on the upper aspect of the bundle (approximately $50 \mathrm{~mm} \mathrm{x}$ $40 \mathrm{~mm}$ ) towards the distal region. In total, 14 layers of wrapping were visually identified comprising eight different types of linen (Table 1). 
Table 1. Table showing the linen types identified on Ha6370, with 1 being the outermost and 8 being the innermost

\begin{tabular}{ccl}
\hline Type & Layers & Description \\
\hline 1 & $1,2,3,4$ & Close, even weave of one fabric type. \\
\hline 2 & $5,6,7$ & Very close, even, tight weave. \\
\hline 3 & 8 & Large elongated weave. Appears to be coated. \\
\hline 4 & 9 & Very pale colour, softer weave on a diagonal slant. \\
\hline 5 & 10,11 & Very close weave, similar to type 4 but thicker threads used. \\
\hline 6 & 12 & Very loose weave, light brown colour with uneven coated areas. \\
\hline 7 & 13 & $\begin{array}{l}\text { Very fine weave with even warp and weft of thick thread. Dark } \\
\text { brown, ? resin coated. }\end{array}$ \\
\hline 8 & 14 & $\begin{array}{l}\text { Very soft cream colour, uncoated fabric of even close weave. } \\
\text { Closest to the core this appears to be laid longitudinally and has a } \\
\text { fluffy texture. }\end{array}$ \\
\hline
\end{tabular}

The miniature mummy was studied using both non-invasive and minimally invasive methods to determine the composition and homogeneity of the bundle. 9 samples (measuring approximately $5 \mathrm{~mm}$ ) were removed for analysis ( 7 from the object and 2 from debris inside the coffin) in July 2010 (Table 2).

Table 2. Table showing the samples removed from the mummy for analysis

\begin{tabular}{|c|c|}
\hline Sample No. & Sample Location \\
\hline 1 & $\begin{array}{l}\text { Middle layer of bandages from the disturbed section at the rear of the } \\
\text { bundle }\end{array}$ \\
\hline 2 & ? Resin and paint from the front/side of the head - mask area \\
\hline 3 & Plaster and coating from the rear of the head \\
\hline 4 & $\begin{array}{l}\text { Bandage from the innermost layer of the disturbed section at the rear of } \\
\text { the bundle }\end{array}$ \\
\hline 5 & $\begin{array}{l}\text { Outermost layer of bandages from the disturbed layer at the rear of the } \\
\text { bundle }\end{array}$ \\
\hline 6 & Debris from the wrappings and inside the coffin \\
\hline 7 & Debris from the wrappings and inside the coffin \\
\hline 8 & Innards from the disturbed section \\
\hline 9 & Innards from the disturbed section \\
\hline
\end{tabular}

Diagnostic radiography was performed at the Manchester Royal Infirmary. Conventional radiographs (X-ray) were obtained in two opposing planes anterior posterior and lateral $-57 \mathrm{kV}, 1 \mathrm{mAs}$ with a focal spot size of $0.6 \mathrm{~mm}$ (Philips medical Systems, Best, the Netherlands). Computed tomography (CT) 
was conducted using a General Electric LightSpeed 32 scanner (GE, Madison, WI) at slice thicknesses of $0.625 \mathrm{~mm}$, and dosage of $120 \mathrm{kV}$ at $200 \mathrm{mAs}$.

$\mathrm{X}$-ray demonstrated that the bundle contained no human or animal skeletal material, therefore classifying the object as a pseudo-mummy (4). A central core constructed from a dense material of unknown origin was clearly visible, as were the parameters of the facial mask applied to the exterior of the bundle (Fig. 2). A 'false foot', mimicking those given to sarcophagi, statues and mummy bundles throughout Egyptian history, was visible. The extensive area of damage, the displacement of material and the presence of an air void associated with the damaged area, were clearly defined.

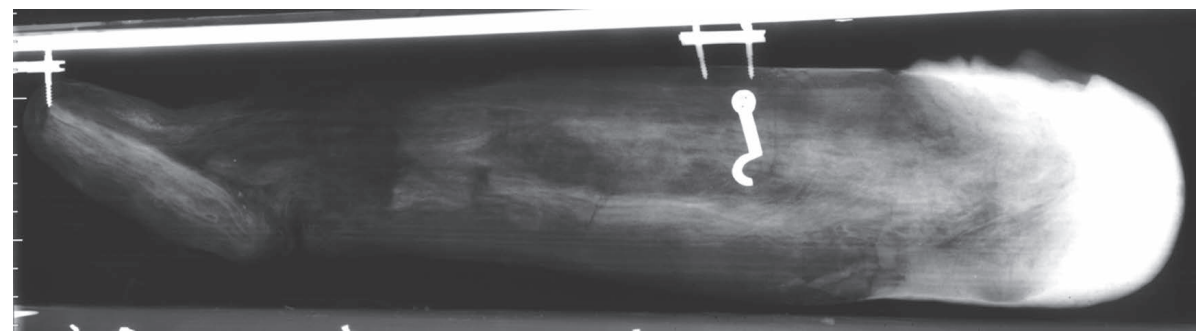

Figure 2. Lateral radiograph of Ha6370 showing the composition of the bundle and the parameters of the mask (image courtesy Manchester Royal Infirmary, McKnight 2010).

The transverse axial CT sections defined the layers of bandaging clearly (Fig. 3) and revealed air pockets and dense inclusions incorporated within the material used to create the mask (Fig. 4). This appears to have been applied in various thicknesses and extends further at the anterior and posterior aspects than it does laterally. The material has been modelled to create the stylised features of a human face - nose, eyes, brow ridge and lips.

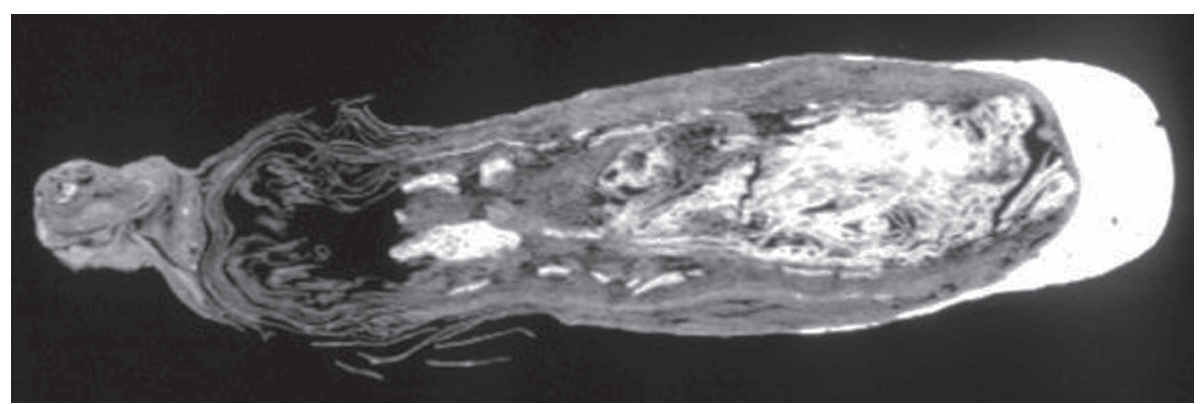

Figure 3. CT coronal reformation showing the central core, the area of damage, the facial mask and the multiple layers of bandaging (image courtesy Manchester Royal Infirmary, McKnight 2010). 


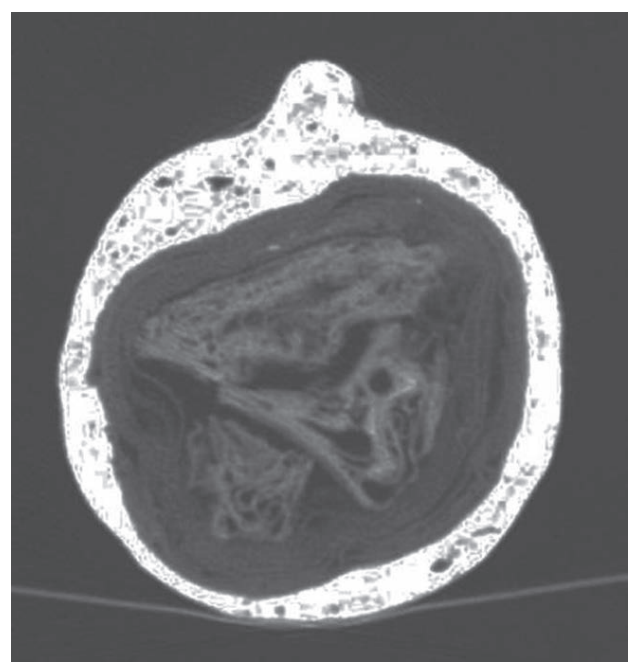

Figure 4. Transverse axial section through the head showing the mask composition (image courtesy Manchester Royal Infirmary, McKnight 2010).

Volume rendering produced images showing the central core of granular material around which the bandages ( $<30 \mathrm{~mm}$ in thickness) have been applied. The mask appears to be formed from a radiodense material.

Samples were analysed microscopically under white light (Carl Zeiss AG, Weimar, Germany) and ultraviolet light (Leitz, Wetzlar, Germany) in order to assess the homogeneity of the samples. Analysis revealed, particularly at the edges of the samples, evidence of fibrous material trapped within the gypsum used to create the mask. Bituminous fragments were identified in the debris samples.

Microscopic analysis showed that the gypsum used to create the mask had fractured as it dried, allowing a thin layer of tin on the inner surface to permeate (Fig. 5). The tin appeared shiny under the plane-polarised light, but black when polarised.

The Environmental Scanning Electron Microscopy (ESEM) and Energy Dispersive Spectroscopy (EDS) was conducted using an acceleration voltage of $15 \mathrm{kV}$ on organic materials, $20 \mathrm{kV}$ on inorganic materials and water pressure of 0.5 torr (Philips NV, Holland). Samples from the core and surrounding bandage layers were examined to ascertain how the 'body' of the mummy was constructed. All the samples were found to be constructed of linen, identified by the continuous even spacing of nodes. The outermost bandage layer was thickly coated with a compound of clay, mud and plaster (Fig. 6), although the mid-layers were completely absent of any coating (Fig. 7). Macroscopically, the innermost bandage layer appeared white compared to the more yellowed outer layers. Evidence of degradation was visible in the sample from the inner layer 
with intercellular collapse of the fibres (Fig. 8). As this layer was disturbed, unsurprising the fibres began to degrade due to exposure without the presence of any protective coating. Small fibres from the innermost layer were found to be clumped together with a compound of clay, mud and plaster similar in appearance to that coating the outer layers (Fig. 9). The central core, base-form, was constructed from a mass of linen fibres coated with clay/mud (Fig. 10). The smooth outer surface indicated it had been constructed and left to set prior to further binding layers being applied.

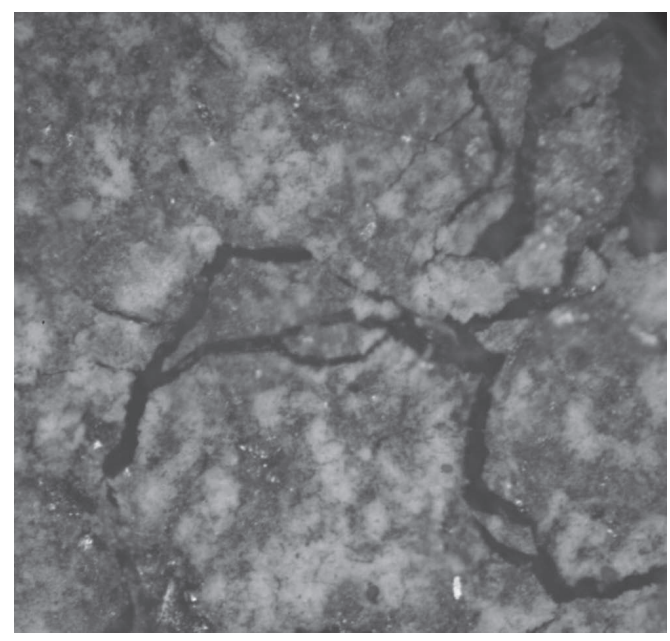

Figure 5. Microscopic image showing the gypsum plaster used to create the mask and the presence of the tin (appears black) within the fractures (8x magnification. Sample 2. Reflected white light / crossed polars) (image by Lidija McKnight).
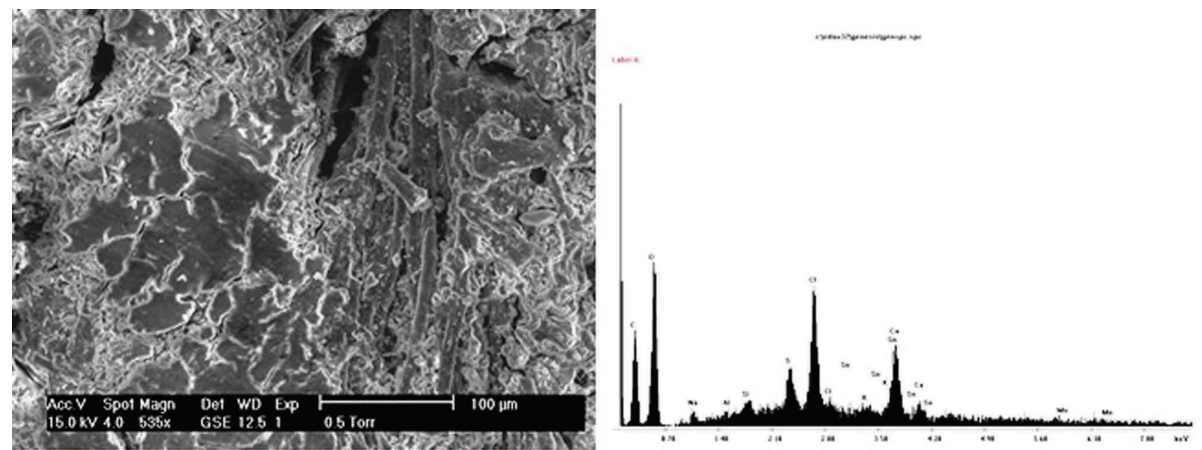

Figure 6. The outermost bandage layer, with fibres covered with mud and a calcareous material (Sample 5, ESEM) The high concentrations of $\mathrm{Ca}, \mathrm{O}$ and $\mathrm{S}$ are suggestive of $\mathrm{CaSO}_{4}$, as the hydrated form, gypsum, anhydrous form anhydrite, or the intermediary hydration mineral, bassanite (Sample 5, EDX) (image by Lidija McKnight). 


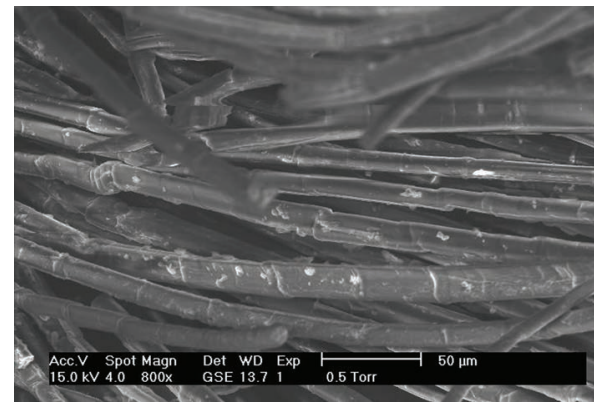

Figure 7. The mid-layers of the wrappings clearly show the flax fibres with diagnostic nodes (Sample 1, ESEM) (image by Lidija McKnight).

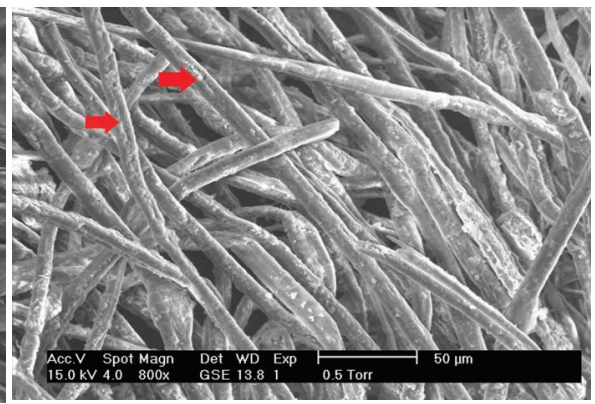

Figure 8. Fibres from the innermost layer show signs of degradation (arrows) (Sample 4, ESEM) (image by Lidija McKnight).
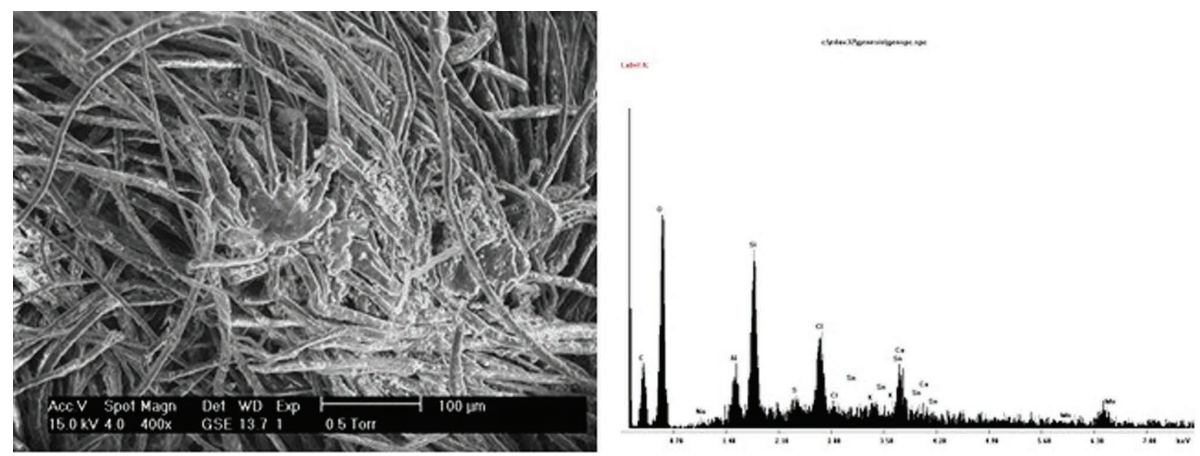

Figure 9. Fibres from the innermost layer adhered with clay ( $\mathrm{Si}, \mathrm{Al}$, and $\mathrm{O}$ ) and a calcium sulphate plaster. The $\mathrm{Cl}$ peak is suggestive of salt $(\mathrm{NaCl})$. The $\mathrm{Sn}$ peak will be discussed later (Sample 4, ESEM and EDX) (image by Lidija McKnight).
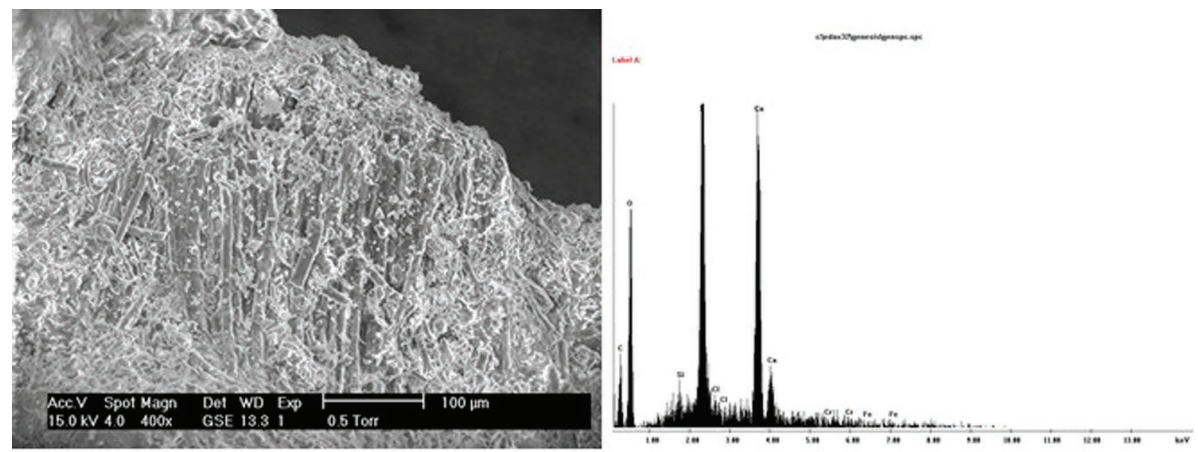

Figure 10. Fibres / linen bundled together and adhered with clay (gypsum-bassaniteanhydrite) to form a base for the bundle (Sample 9, ESEM and EDX) (image by Lidija McKnight). 
As the middle layer was uncoated it was possible to identify that the linen had been produced from S-spun flax yarn (Fig. 11), which is considered to be unique to flax and characteristic of Pharaonic textiles (1).

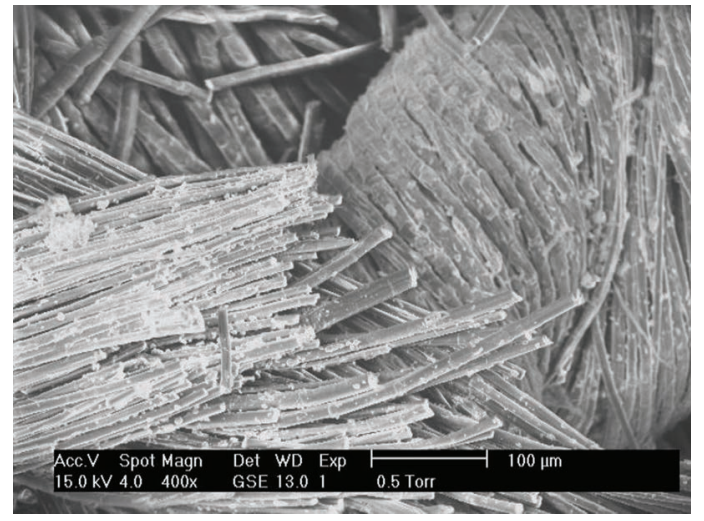

Figure 11. The presence of S-plied yarn (Sample 1, ESEM) (image by Lidija McKnight).

Two samples were obtained from the mask, one from the front (Sample 2) and one from the rear (Sample 3) to ascertain consistency in its construction. Both samples indicated a calcium sulphate phase, such as Gypsum Plaster (i.e. Plaster of Paris). The outer 'face' side of the mask was constructed of a similar material to that of the inner structure of the bundle - linen coated with clay; yet the mask was also coated with gypsum (Fig. 12). The underside of the mask, which had adhered to the bundle, demonstrated evidence for a thin and patchy layer of tin (Fig. 13).
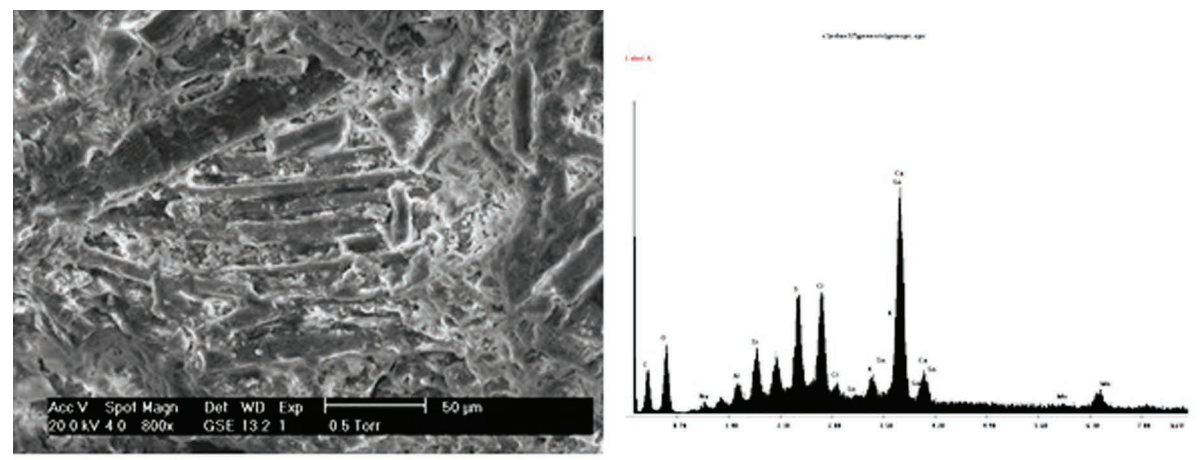

Figure 12. The outer side of the mask shows fibres coated with clay and gypsum (Sample 2, ESEM and EDX) (image by Lidija McKnight). 

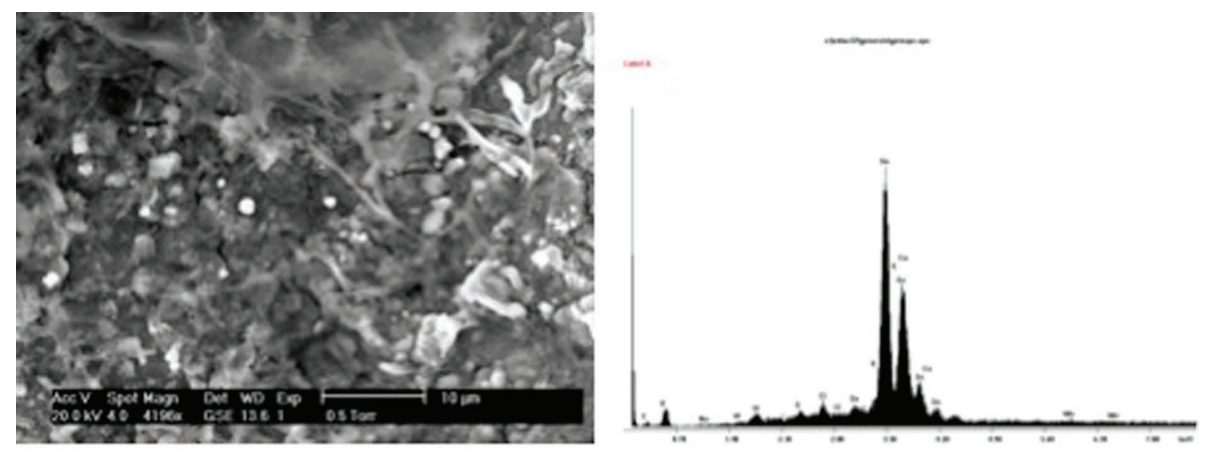

Figure 13. The droplets of tin appear bright white (Sample 3, ESEM and EDX) (image by Lidija McKnight).

\section{DISCUSSION}

The analysis of Ha6370 revealed that it is in fact a pseudo-mummy as it contained no human or animal skeletal material (4). The variety of linen layers and spinning techniques used suggest it is more likely to be ancient in origin, rather than a modern fake (1). This observation is based on comparable radiographic observations with mummified animals from ancient Egypt studied by the author $(3,4)$. Both mummified animal remains and pseudo-animal mummies known to be ancient Egyptian in origin possess multiple layers of wrapping applied at a variety of thicknesses and densities.

The analysis of mask samples suggested that the material was a form of gypsum plaster to which paint had been applied to emphasise the facial features and make the object appear more realistic as a human mummy. The irregular layer of tin detected on the reverse side of the mask was peculiar and may have been applied to prevent deterioration. Alternatively, the tin may have transferred from a tin-plated steel or iron mould used to create the mask and prevent reddening of the gypsum by rust.

Tinning in the ancient world has been recorded; however, it is generally confined to high status goods and functional objects. Mummy number E6665 (Katebet) from the British Museum (c. $18^{\text {th }}-19^{\text {th }}$ dynasty) possesses a winged Isis pectoral and shabti, both showing evidence of tin-foil decoration (pers. comm. - D. Piombino-Mascali). Tinning associated with the production of armour is reported in the Middle Ages, with examples such as a shield (c. 13601400) discovered during excavations at the old Billingsgate Fish Market site, London, UK (000129). Assessment of the construction and decoration of the wooden coffin and the mask indicated that they post-date the wrapped bundle, 
and are modern in origin. The appearance of tin on the underside of the mask may suggest that its application was by chance rather than design, indicating accidental transference of tin. The application of the mask could represent a recent addition to the bundle, applied when tinning became more widespread, and possibly even after the bundle was exported from Egypt. Further work is required on this artefact in the hope of being able to identify where the mask may have been manufactured and if it is in fact contemporary with the wrapped bundle itself. Dating techniques such as accelerator mass spectrometry (AMS) would confirm the authenticity of the mummy bundle, and provide a date for the mask. In addition, infra-red photography of the paint used on the mask would aid in the interpretation of the decorative pigments, and would enhance the dating criteria (pers. comm. - J. Klocke).

This is the first time that a mummy of this nature has been studied using scientific techniques, and research on comparable artefacts known in other museum collections $(2,4,5)$ would help to establish the nature of this group of specimens and from where and when they might have originated.

\section{ACKNOWLEDGEMENTS}

The authors would like to thank the curatorial and conservation team at Bristol Museum and Art Gallery, Keith Hall at Hall Analytical, Stephanie AthertonWoolham, Jens Klocke and Dario Piombino-Mascali. Grateful thanks go to Professor Judith Adams, Consultant Radiologist at the Manchester Royal Infirmary and her team.

\section{REFERENCES}

1. Eastwood G. (1988). The Textiles. In: Dawson D.P., Giles S., Ponsford M.W. (eds), Horemkenesi: May he live forever! The Bristol Mummy Project (123). Bristol Museum and Art Gallery. Bristol.

2. Germer R. Kischkewitz H., Lüning M. (1994). Pseudo-Mumien der ägyptischen Sammlung Berlin. SAK, 21, 81-94.

3. McKnight L.M. (2010). Imaging Applied to Animal Mummification in Ancient Egypt. BAR International Series 2175, Archaeopress. Oxford.

4. McKnight L.M., Atherton S.D. (2014). How to 'pigeonhole' your mummy - a proposed categorisation system for ancient Egyptian wrapped animal remains based on radiographic evaluation. Yrbk Mummy Studies, 2, 109-116.

5. Quirke S. (1997). Modern Mummies and Ancient Scarabs: The Egyptian Collection of Sir William Hamilton. Journal of the History of Collections, 9(2), 253-262. 
Address for correspondence:

Dr Lidija M. McKnight

KNH Centre for Biomedical Egyptology

University of Manchester

3.503 Stopford Building

Oxford Road, Manchester M13 9PT

UK

E-mail: lidija.mcknight@manchester.ac.uk 